\section{KẾT LUẦN}

Số lần đại tiện/1 tuần ở nhóm can thiệp tăng lên 0,5 lần so với ban đầu, ở nhóm chứng không có sự cải thiện, sự khác biệt giữa hai nhóm tại thời điểm T8 là có ý nghĩa thống kê $(p<0,05)$.

Về tính chất phân, nhóm can thiệp giảm còn $5,6 \%$ trẻ có phân dạng 2 và $35,2 \%$ phân dạng 3 , nhóm chứng giảm còn $8,3 \%$ phân dạng 2 và $41,7 \%$ phân dạng 3 .

Tình trang són phân, nhin đi ngoài ở nhóm can thiệp tốt hơn ở nhóm chứng. Tuy nhiên, sự khác biệt không có ý nghĩa thống kê.

Có sự cải thiện đáng kể về phân cứng, phân to ở nhóm can thiệp so với nhóm chứng $(p<0,05)$ sau 12 tuần can thiệp.

\section{TÀI LIỆU THAM KHẢO}

1. Benninga, M.A., Voskuijl, W.P., and Taminiau, J., (2004). Childhood constipation: is there new light in the tunnel? Journal of pediatric gastroenterology and nutrition. 39(5): p. 448-464.

2. Rajindrajith, S., Devanarayana, N.M., Perera, B.J.C., et al., (2016). Childhood constipation as an emerging public health problem. World journal of gastroenterology. 22(30): p. 6864.

3. Nguyến Thị Phương Mai (2013). Nghiên cứu đặc điểm lâm sàng và nguyên nhân gây táo bón ở trẻ em, Luân văn thạc sĩ, Trường Đai học Y Hà Nôii.

4. Viện Dinh dưỡng (2020). Thổng kê về tình trạng dinh dướng của trẻ em qua các năm.

5. Rasquin, A., Di Lorenzo, C., Forbes, D., et al., Childhood functional gastrointestinal disorders: child/adolescent. Gastroenterology, 2006. 130(5): p. $1527-1537$.

6. Coccorullo, P., Strisciuglio, C., Martinelli, M., et al., (2010). Lactobacillus reuteri (DSM 17938) in infants with functional chronic constipation: a double-blind, randomized, placebo-controlled study. The Journal of pediatrics. 157(4): p. 598602.

7. Đố Thị Minh Phương (2014). Nghiên cứu một số yếu tố nguy cơ và đánh giá hiệu quả điều trị táo bón chức năng ở trẻ em tại bệnh viện Nhi Trung Ương, Luận văn thạc sĩ, Trường Đại học Y Hà Nội.

8. Tabbers, M., de Milliano, I., Roseboom, M., et al., (2011). Is Bifidobacterium breve effective in the treatment of childhood constipation? Results from a pilot study. Nutrition journal. 10(1): p. 1-5.

\title{
NGHIÊN CỨU TỶ LÊ TĂNG ĐƯỜNG HUYẾT Ở BỆNH NHÂN NHỒI MÁU NÃO TRONG 3 NGÀY ĐÂU
}

\section{Đỗ Đức Thuần*, Đinh Công Trường**, Nguyễn Thị Phi Nga* \\ TÓM TẮT \\ Mục tiêu: Nghiên cứu tỷ lệ tăng đường huyết ở bệnh nhân nhồi máu não trong 3 ngày đâu. Đối tượng và phương pháp nghiên cứu: nghiên cứu tiến cứu, mô tả cắt ngang 246 bệnh nhân nhồi máu \\ SUMMARY \\ STUDY ON THE RATE OF HYPERGLYCEMIA IN ISCHEMIC STROKE PATIENTS IN THE FIRST 3 DAYS} não 3 ngày đầu tại Khoa Đột quỳ, Bệnh viện 103 từ tháng 5 năm 2017 đến tháng 8 năm 2018. Kết quả: Tỷ lệ tăng đường huyết trong nhóm nghiên cứu là $35,37 \%$. Tỷ lệ tăng đường huyết ở bệnh nhân nhồi máu não có đái tháo đường là $73,75 \%$, không có đái tháo đường là $16,86 \%$. Tỷ lệ tăng đường huyết ở bệnh nhân nhồi máu não có rung nhỉ 47,62\%, Glasgow $\leq 9$ điểm $75 \%$, tắc động mạch não giữa $59,09 \%$ và tắc động mạch thân nền là $71,42 \%$. Kết luân: Tăng đường huyết găp $35,37 \%$ bệnh nhân nhồi máu não trong 3 ngày đâu, tỳ lệ tăng đường huyết chiếm tỷ lệ cao ở bệnh nhân có tiên sử đái tháo đường, lâm sàng nhồi máu não nặng.

Từ khóa: Nhồi máu não, tăng đường huyết

\footnotetext{
*Bênh viện Quân y 103,

**Bệnh viện Nội tiết Trung Uơng,

Chịu trách nhiệm chính: Đỗ Đức Thuần

Email: dothuanvien103@gmail.com

Ngày nhận bài: 14.9.2021

Ngày phản biện khoa học: 10.11.2021

Ngày duyệt bài: 18.11.2021
}

Objective: Study on the rate of hyperglycemia in ischemic stroke patients in the first 3 days. Subject and method: Prospective, cross-sectional study of 246 ischemic stroke patients in the first 3 days in the stroke department of Hospital №103 from july 2017 to August 2018. Result: The rate of hyperglycemia in the study group was $35.37 \%$. The rate of hyperglycemia in ischemic stroke patients with diabetes is $73.75 \%$, without diabetes is $16.86 \%$. The patients with atrial fibrillation was $47.62 \%$, Glasgow $\leq$ 9 points was $75 \%$, middle cerebral artery occlusion $59.09 \%$ and basilar artery occlusion was $71.42 \%$. Conclution: Hyperglycemia occurs in $35.37 \%$ of ischemic stroke patients in the first 3 days, the rate of hyperglycemia accounts for a high proportion in patients with a history of diabetes, clinical severe cerebral infarction.

Key words; ischemic stroke, hyperglycemia

I. ĐẶT VẤN ĐỀ

Đột quy não đã và đang trở thành vấn đề quan trọng của y học ở tất cả các quốc gia trên thế giới do bệnh có tỷ lệ mắc, tỷ lệ tử vong cao 
và có mức độ di chứng nặng nề nhất trong các bệnh lý nội khoa. Ở Hoa Kỳ mỗi năm có khoảng 800.000 bệnh nhân đột quy não trong đó có 600.000 đột quy lần đâu, tỷ lệ mắc đột quy tăng theo tuổi, dự kiến số lượng các ca mắc đột quy. tăng lên gấp đôi vào những năm 2030, gần đây các nghiên cứu còn thây đột quy có xu hướng trẻ hóa [1]. Đột quy nhồi máu não chiếm $85 \%$ tổng số đột quy não [1]. Trong những năm gần đây các nghiên cứu còn nhận thấy tăng đường ở bệnh nhân đột quy. cấp có ảnh hưởng xấu đến kết quả điều trị của bệnh nhân đột quy. não [2]. Cùng với thế giới chăm sóc và điều trị đột quy tại Việt nam đã có những tiến bộ rõ rệt, nhưng kiểm soát đường huyết ở những bệnh nhân đột quy. vẫn còn nhiều khó khăn. Cho đến thời điểm hiện tại chưa có nghiên cứu nào được công bố tỷ lệ và kiểm soát đường huyết ở bệnh nhân đột quy. não cấp. Để góp phần nâng cao hiệu quả điều trị bệnh nhân đột quy chúng tôi thực hiện đề tài nghiên cứu tỷ lệ tăng đường huyết ở bệnh nhân nhồi máu não trong 7 ngày đâu.

\section{II. ĐỐI TƯƠ'NG VÀ PHƯƠNG PHÁP NGHIÊN CỨU}

2.1. Đối tượng nghiên cứu. 246 bệnh nhân nhồi máu não được điêuu trị tại tại Khoa Đột quy. Bệnh viện Quân y 103 trong thời gian từ tháng 05 năm 2017 đến tháng 08 năm 2018

Bệnh nhân được chọn vào nghiên cứu khi có đủ 3 tiêu chuẩn:

- Bệnh nhân nhồi máu não được chẩn đoán theo định nghĩa đột quy. não của WHO năm 1980.

- Trên hình ảnh CT sọ não có hình ảnh nhồi máu não.

- Thời gian từ lúc khởi phát đột quy đến khi vào viện là 72 giờ
2.2. Phương pháp nghiên cứu. Nghiên cứu được thiết kế theo phương pháp tiến cứu, mô tả cẳt ngang

Tiêu chuẩn chẩn đoán tăng đường huyết: bệnh nhân xét nghiệm đường huyết ở thời điểm vào viện có đường huyết $>8,0 \mathrm{mmol} / \mathrm{l}$. Xét nghiệm được thực hiện trên máy xét nghiệm đường huyết mao mạch nhanh tại giường bệnh, ngay khi người bệnh vào viện.

\section{KẾT QUẢ NGHIÊN CỨU VÀ BÀN LUẬN}

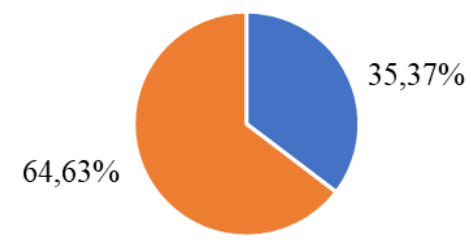

- Tăng đường huyết - Không tăng

Biểu đồ 1: Tỷ lệ tăng đường huyết ở nhóm nghiên cứu

Trong nghiên cứu của chúng tôi gặp tỷ lệ tăng đường huyết là $35,37 \%$, trong nghiên cứu của Muir K.W và cộng sự với tỷ lệ tăng đường huyết là $42,6 \%$ cao hớn trong nghiên cứu của chúng tôi, sự khác biệt được cho là do quần thể nghiên cứu, đối tượng nghiên cứu, và trong nghiên cứu Muir K.W và cộng sự đối tương nghiên cứu là những bệnh nhân đột quỵ trong 24 giờ đầu [3], nghiên cứu của chúng tôi đối tượng nghiên cứu ở 3 ngày đầu sau khởi phát đột quy.

- Có 96 bệnh nhẩn tuổi từ 40 đến 60 với tỷ lệ tăng đường huyết $36,45 \%$ và 150 bệnh nhân tuổi 61 đến 85 với tỷ lệ tăng đường huyết 34,67\%. Tỷ lệ TĐH không khác biệt ở hai nhóm tuổi trong nghiên cứu

Bảng 1. Tỷ lệ tăng đường huyêt theo giới, tuổi và các yếu tố nguy cơ

\begin{tabular}{|c|c|c|c|}
\hline Yếu tố nguy cơ & $\begin{array}{c}\text { Tỷ lệ TĐH ở nhóm có } \\
\text { YTNC }\end{array}$ & $\begin{array}{c}\text { Tỷ lệ TĐH ở nhóm } \\
\text { khống có YTNC }\end{array}$ & $\mathbf{P}$ \\
\hline Giới nam & $34,28(48 / 140)$ & $36,79(39 / 106)$ & $>0,05$ \\
\hline Tăng huyết áp & $36,41(75 / 206)$ & $30,0(12 / 40)$ & $>0,05$ \\
\hline Đái tháo đường & $73,75(59 / 80)$ & $16,86(28 / 166)$ & $<0,05$ \\
\hline Hút thuốc lá & $35,71(20 / 56)$ & $35,26(67 / 190)$ & $>0,05$ \\
\hline Rung nhĩ & $47,62(20 / 42)$ & $32,84(67 / 204)$ & $<0,05$ \\
\hline
\end{tabular}

Trong bảng 1 ở bệnh nhân nhồi máu não 3 ngày đầu, tỷ lệ tăng đường huyết ở giới nam là $34,28 \%$, ở giới nữ là $36,79 \%$, khác biệt không có ý nghĩa thống kê với $p>0,05$. Tỷ lệ tăng đường huyết ở bệnh nhân có tăng huyết áp, hút thuốc lá so với những bệnh nhân không tăng huyết áp và không hút thuốc lá sự khác biệt là không có ý nghĩa thống kê với $p>0,05$.
- Cũng tại bảng 1 ta thấy ở bênh nhân nhồi máu não 3 ngày đầu trong nghiên cứu, nhóm đái tháo đường có tỷ lệ tăng đường huyết là $73,75 \%$ cao hơn nhóm khổng đái tháo đường với tỷ lệ tăng đường huyết là $16,86 \%$, khác biệt có ý nghĩa thống kê với $p>0,05$. Đái tháo đường được xem là một nguy cơ gây nhồi máu não, mặt khác nhiều nghiên cứu thấy đái tháo đường 
là một nguy cơ gây tăng đường huyết ở bệnh nhân nhồi máu não như nghiên cứu của Shimoyama, T. và cộng sự năm 2014 với 1829 bệnh nhân nhồi máu cấp trong 24 giờ đầu thấy có 143 bệnh nhân $(38,1 \%)$ có tăng đường huyết , trong đó bệnh nhân đái tháo đường có tăng đường huyết là $40,6 \%$ và bệnh nhân nhồi máu não cấp không đái tháo đường có tăng đường huyết là 19,8\%, khác biệt có ý nghĩa thống kê. [4]. So với nghiên cứu của Shimoyama, T. và cộng sự, bệnh nhân nhồi máu não có đái tháo đường có tỷ lệ tăng đường huyết của chúng tôi cao hơn. Điêu đó có thể do sự kiểm soát đường huyết ở bệnh nhân đái tháo đường trong nghiên cứu của Shimoyama, T. và cộng sự tốt hơn, đối tượng nghiên cứu của chúng tôi là bệnh nhân đột quy trong 3 ngày đầu, trong nghiên cứu của Shimoyama, $T$. và cộng sự là 24 giờ đâu. Có $16,86 \%$ bệnh nhân đột quỵ không có tiền sử đái tháo đường nhưng có tăng đường huyết sau đột quy. Cơ chế tăng đường huyết ở bệnh nhân đột quỵ không có tiền sử đái tháo đường là sự phản ứng không đặc hiệu hay tăng tiết một số hoocmon liên quan đến tăng đường huyết như cortisol hay hoocmon orepinephrine. Các hoocmon này ảnh hưởng đến chuyển hóa glucose nên làm tăng đường huyết [5]. Ngoài ra tăng đường huyết ở bệnh nhân đột quy cấp như còn được cho là do: rối loạn tính tự điểu hòa của cơ thể, trung tâm điều hòa glucose trong não sau đột quy, rối loạn trục dưới đồi tuyến yến và tuyến thượng thận, rối loạn chuyển hóa sau tổn thương mổ và còn có sự tằng tiết các cytokin sau đột quỵ làm tăng tính đề kháng với insulin từ đó gẩy tăng đường huyết sau đột quy. [6]. Trong nghiên cứu của chúng tôi thấy tỷ lệ tăng đường huyết ở bệnh nhân nhồi máu não có rung nhĩ là 47,62\%, cao hơn tỷ lệ tăng đường huyết ở bệnh nhân nhồi máu não không có rung nhĩ $(32,84 \%)$, khác biệt có ý nghĩa thống kê với $p<0,05$. Theo Gustavo Saposnik bệnh nhân nhồi máu não do rung nhĩ thường có ổ nhồi máu lớn hơn, lâm sàng nặng hơn, có nguy cơ chảy máu não chuyển dạng cao hơn nhồi máu não không do rung nhĩ [7]. Bệnh nhân nhồi máu não có lâm sàng nặng là yểu tố nguy cơ gây tăng đường huyết sau đột quy.

Bảng 2. Tỷ lê tăng đường huyêt theo đặc điểm lâm sàng và hình ảnh tổn thương

\begin{tabular}{|c|c|c|c|}
\hline Đặc điểm lâm sàng và hình ảnh & $\begin{array}{c}\text { Tỷ lệ̣ TĐH nhóm có } \\
\text { ĐĐLS, HA }\end{array}$ & $\begin{array}{c}\text { Tỷ lệ TĐH nhóm } \\
\text { khống có ĐĐLS, HA }\end{array}$ & p \\
\hline Glasgow $\leq 9$ điểm & $75,0(6 / 8)$ & $34,03(81 / 238)$ & $<0,05$ \\
\hline Nhồi máu chuyển dạng chảy máu & $35,48(11 / 31)$ & $35,35(76 / 215)$ & $>0,05$ \\
\hline Tắc động mạch não giữa M1 & $59,09(13 / 22)$ & $33,06(74 / 224)$ & $<0,05$ \\
\hline Tắc động mạch thân nền & $71,42(5 / 7)$ & $34,31(82 / 239)$ & $<0,05$ \\
\hline
\end{tabular}

Trong bảng 2, tỷ lệ bệnh nhân nhồi máu não có tăng đường huyết ở nhóm Glasgow $\leq 9$ điểm, tắc động mạch não giữa đoạn $M 1$, tắc động mạch thân nền cao hơn có ý nghĩa thống kể so với nhóm Glasgow > 9 điểm, không có tắc động mạch não giữa đoạn $\mathrm{M} 1$, không có tắc động mạch thân nền. Những bệnh nhân có Glasgow $\leq 9$ điểm, tắc $M 1$ và thân nền là những bệnh nhân nhồi máu não có diễn biến nhanh, đột ngột và lâm sàng nặng. Nghiên cứu của Marik P.E và cộng sự năm 2013 cũng thây rằng đột quy càng nặng thì càng có nguy cơ cao biến đổi hooc mon trục dưới đồi tuyến yên từ đó gây tăng đường huyết [8]. Bệnh nhân nhân nhồi máu não có chuyển dạng chảy máu và không chuyển dạng chảy máu chúng tôi không thây khác biệt về tỷ lệ tăng đường huyết giữa hai nhóm trền thong kề y học.

\section{KẾT LUẦN}

Nghiên cứu về tỷ lệ tăng đường huyết ở 246 bệnh nhân nhồi máu não trong 3 ngày đầu từ tháng 5 năm 2017 đến tháng 8 năm 2018, chúng tôi thấy: Tỷ lệ tăng đường huyết trong nhóm nghiên cứu là 35,37\%. Tỷ lệ tăng đường huyết ở bệnh nhân nhồi máu não có đái tháo đường là $73,75 \%$, không có đái tháo đường là $16,86 \%$. Tỷ lệ tăng đường huyết ở bệnh nhân nhồi máu não có rung nhỉ $47,62 \%$, Glasgow $\leq 9$ điểm $75 \%$, tắc động mạch não giữa $59,09 \%$ và tắc động mạch thân nền là $71,42 \%$. Cao hơn có ý nghĩa thống kê so với bệnh nhân nhồi máu não không có rung nhĩ, Glasgow $>9$ điểm, không tắc thân nền và động mạch não giữa đoạn M1.

\section{TÀI LIỆU THAM KHẢO}

1. Wade S.S., Joey D.E., Johnston S.C. (2013), "Cerebrovascular Diseases", HARRISON'STM NEUROLOGY IN CLINICAL MEDICINE, 3rd Edition, McGraw-Hill Education, pp. 256-294.

2. Powers W.J., Rabinstein A.A., Ackerson T. et al (2018), "2018 Guidelines for the Early Management of Patients With Acute Ischemic Stroke: A Guideline for Healthcare Professionals From the American Heart Association/American Stroke Association", Stroke, 49(3), pp. e46-e99. 
3. Muir K.W., McCormick M., Baird T. et al (2011), "Prevalence, Predictors and Prognosis of Post-Stroke Hyperglycaemia in Acute Stroke Trials: Individual Patient Data Pooled Analysis from the Virtual International Stroke Trials Archive (VISTA)", Cerebrovascular Diseases Extra, 1(1), pp. 17-27.

4. Shimoyama T., Kimura K., Uemura J. et al (2014), "Elevated glucose level adversely affects infarct volume growth and neurological deterioration in non-diabetic stroke patients, but not diabetic stroke patients", European Journal of Neurology, 21(3), pp. 402-410.

5. Lindsberg P.J., Roine R.O. (2004),
"Hyperglycemia in Acute Stroke", Stroke, 35(2), pp. 363-364.

6. Garg R., Chaudhuri A., Munschauer F. et al (2006), "Hyperglycemia, Insulin, and Acute Ischemic Stroke", Stroke, 37(1), pp. 267-273.

7. Saposnik G., Gladstone D., Raptis R. et al (2013), "Atrial fibrillation in ischemic stroke: predicting response to thrombolysis and clinical outcomes", Stroke, 44(1), pp. 99-104.

8. Marik P.E., Bellomo R. (2013), "Stress hyperglycemia: an essential survival response!", Critical care (London, England), 17(2), pp. 305-305.

\section{ĐÁNH GIÁ KẾT QUẢ ĐIỀU TRI TRĨ NộI CHẢY MÁU BẰNG THẮT VÒNG CAO SU QUA MÁY NộI SOI ỐNG MỀM}

\section{TÓM TẮT}

Mục tiêu: Mục đích của nghiên cứu là đánh giá hiêu quả lâm sàng và biến chứng của phương pháp điểu trị không phấu thuật với trĩ mức độ trung bình (I, II và III) bằng phương pháp nội soi thắt vòng cao su (ERBL). Đối tượng và phương pháp: Tổng số nghiên cứu trên 34 bệnh nhân tuổi trung bình 45,7 tuổi được sử dung phương pháp ERBL bằng máy nôi soi ống mềm và bộ thắt vòng cao su dùng cho thắt tĩnh mạch thực quản, tất cả bệnh nhân được theo dõi đánh giá kết quả lâm sàng và biến chứng. Kết quả: Kết quả nghiên cứu có 16 bênh nhân trĩ nội đô I, 10 bênh nhân trĩ nội độ II, 8 bệnh nhân trĩ nội độ İII. Tất cả bênh nhân đều có trĩ chảy máu, 4(19\%) bểnh nhân có ngứa hậu môn và $10(47.6 \%)$ bệnh nhân có dấu hiêu sa búi trĩ đây lên được. Sau điều tri ERBL triệu chứng chảy máu được cải thiện ở 30(88.1\%) bệnh nhân. Tất cả bệnh nhân cần phải thực hiên điều trị 1 lần, hoặc 2 lần, số vòng trung bình sử dụng 2,9 vòng, triệu chứng đau sau thắt vòng là thường gặp $21(61.8 \%)$ bênh nhân, hâuu hết giảm nhe sau đó. Kềt luận: Phương pháp thắt vòng cao su có sử dụng máy nôi soi mềm là phương pháp dễ thực hiện, an toàn và hiệu quả trong điều trị bênh lý trĩ có triêu chứng.

Tư khóa: Trĩ, thắt vòng cao su, nội soi ống mềm.

\section{SUMMARY}

\section{RUBBER BAND LIGATION FOR TREATMENT OF BLEEDING INTERNAL HEMORRHOIDS USING FLEXIBLE GASTROSCOPY}

Objective: The purpose of this study was the evaluation of the efficacy, clinical outcome

\footnotetext{
${ }^{1}$ Trung tâm tiêu hóa gan mật bệnh viện Bạch mai ²Bênh viên đa khoa tỉnh Bắc Ninh Chịu trách nhiệm chính: Nguyễn Công Long Email: nguyenconglongbvbm@gmail.com Ngày nhận bài: 15.9.2021

Ngày phản biện khoa học: 10.11.2021

Ngày duyệt bài: 19.11.2021
}

\section{Nguyễn Công Long', Nguyễn Hanh Thiện ${ }^{2}$}

complications with non-surgical treatment for intermediate grade (I, II and III) by endoscopic rubber band ligation (ERBL). Subjects and methods: A total 34 patients of mean age 45.7 years were underwent ERBL technique with the aid of a gastroscopy and a kit of elastic rubber bands for esophageal varices. All the patients were follow up and were evaluated technical and clinical efficiency and complications. Results: The obtained results showed that sixteen patients had grade I hemorrhoids, 10 patients had grade II hemorrhoids and 8 patients had grade III hemorrhoids. All the patients were observed with anal bleeding, in which 4 patients $(19 \%)$ was observed with chronic complaints itching and 10 patients $(47.6 \%)$ were observed with prolapse. In particularly, The rectal bleeding and other symptoms were controlled with significantly fewer treatments ERBL had a significantly higher success rate 30 patients $(88.1 \%)$, all patients needed a minimum of 1 treatment and a maximum of 2 treatments, a median of 2.9 bands was used in the procedure. Pain after ligation tended to be more frequent in patients treated with the flexible endoscope $61.8 \%$ (21 patients) but most of the complications are considered of low magnitude, easily resolved. Conclusions: The rubber band ligation using the flexible gastroscopy method was proved to be a feasible with advantages maneuverability, safe and efficient for the treatment of symptomatic hemorrhoid disease.

Keywords: Hemorrhoids, Band ligation, Flexible gastroscopy.

\section{I. ĐĂT VẤN ĐỀ}

Trĩ là rối loạn hậu môn trực tràng hay gặp nhất ở người lớn, là hiên tượng các mach máu vùng hâu môn căng to dễ chảy máu, găp nhiều ở người lao động tĩnh tại, táo bón kéo dài và trên $90 \%$ số bênh nhân được soi trực tràng hay đại tràng được tìm thấy là có trĩ ở các đô khác nhau [1]. Điều trị bảo tồn được cân nhắc ở những 